\title{
Correlation between clinical course and quantitative analysis of the ischemia related artery in patients with unstable angina pectoris, refractory to medical treatment
}

\author{
Results of two randomized trials
}

\author{
Marcel J.B.M. van den Brand ${ }^{1}$, Addy van Miltenburg${ }^{1}$, Menko J. de Boer ${ }^{2}$, \\ L. Ron van der Wieken ${ }^{3}$, Pim J. de Feyter ${ }^{1}$, Maarten L. Simoons ${ }^{1} \&$ \\ The European Cooperative Study Group \\ ${ }^{1}$ Thoraxcenter, Erasmus University and University Hospital Dijkzigt, P.O. Box 1738, 3000 DR Rotterdam; ${ }^{2}$ Depart- \\ ment of Cardiology, de Weezenlanden Ziekenhuis, Zwolle; ${ }^{3}$ Department of Cardiology, Onze Lieve Vrouwen \\ Gasthuis, Amsterdam, The Netherlands
}

Received 5 November 1993; accepted 27 December 1993

Key words: unstable angina, quantitative coronary angiography, thrombolysis, platelet aggregation inhibition

\begin{abstract}
Patients with unstable angina, refractory to intensive medical therapy, are at high risk for developing thrombotic complications, such as recurrent ischemia, myocardial infarction and coronary occlusion during coronary angioplasty. As both platelet aggregation and/or thrombus formation play an important role in this ongoing ischemic process, a monoclonal platelet GPIIb/IIIa receptor antibody (c7E3) or thrombolytic therapy (alteplase) might be able to modify the clinical course and underlying coronary lesion morphology. To evaluate whether alteplase or c7E3 could influence the incidence of complications, we randomized 36 and 60 patients, respectively to alteplase or placebo, or c7E3 or placebo. All patients exhibited dynamic ECG changes and recurrent pain attacks, despite maximal tolerated medical therapy. Patients were randomized in both studies after initial angiography had demonstrated a culprit lesion amenable for angioplasty. After study drug infusion quantitative angiography was repeated and angioplasty performed. Recurrent ischemia during study drug infusion occured in 5, 6, 9 and 16 patients from the alteplase, placebo, c7E3 and placebo group, respectively. Major events defined as death, myocardial infarction or urgent intervention occurred in 7,3,1 and 7 patients, respectively. Two patients died: one in the alteplase group and one in the placebo group from the c7E3 study. The first patient due to retroperitoneal hemorrhage, the second as a result of recurrent infarction. Qualitative angiography showed resolution of clots in the c7E3 group only, while the same group of patients showed in $20 \%$ an improvement in TIMI flow grade, without deterioration in any patient from this group. Quantitative angiography showed a significant improvement in percentage diameter stenosis in the $\mathrm{c} 7 \mathrm{E} 3$ group, which was not observed in all three other groups, although differences between groups were not significant. Alteplase infusion in patients with refractory unstable angina did not change the clinical course, nor the coronary morphology, c7E3 on the other hand, both improved the clinical course and the coronary lesion morphology and rheology in the same category of patients.
\end{abstract}

\section{Introduction}

In 1989 Braunwald provided a classification for patients with unstable angina, based on the clinical circumstances under which the syndrome occurred and the severity of the symptoms [1]. A further subdivision took the intensity of medical treatment and the presence or absence of reversible electrocardiographic changes during anginal attacks into consideration. 
The underlying cause of unstable angina is thought to be rupture and ulceration of a pre existent atherosclerotic plaque, leading to platelet adhesion and aggregation and thrombus formation [2, 3]. In most patients the syndrome can be stabilized with bed rest and antiischaemic and anti-thrombotic therapy [4].

However, in a minority of patients ischemic symptoms continue in spite of intensive medical therapy. Such patients with unstable angina refractory to medical treatment are usually referred for urgent angioplasty or bypass operation, which interventions are associated with a higher complication rate compared with stable or stabilized unstable angina patients $[5,6]$. Prevention and or resolution of platelet aggregates and thrombi may help to prevent ongoing ischemic attacks and angioplasty complications.

The value of administration of thrombolytic therapy in recent myocardial infarction has clearly been demonstrated. It opens occluded coronary arteries, improves left ventricular function and reduces mortality by limiting infarct size [7,8]. As unstable angina and myocardial infarction share a common pathogenetic substrate, it seems reasonable that thrombolytic therapy should ameliorate the syndrome of unstable angina pectoris [9]. Several studies have shown that thrombolytic therapy can reduce the incidence of sudden death, the number of ischemic episodes, and improve the threshold for ischemia during atrial pacing [10-18] in patients with unstable angina. More recent randomized trials found an angiographic improvement after thrombolytic therapy in patients with unstable angina by opening occluded coronary arteries and reducing the incidence of intracoronary thrombi, however without decreasing in hospital cardiac events $[19,20]$.

CentoRx ${ }^{R}$ (c7E3) is a monoclonal antibody that blocks the platelet fibrinogen receptor, glycoprotein IIb/IIIa. By preventing the binding of fibrinogen to the platelet surface, platelet aggregation and platelet thrombus formation are inhibited [21].

We designed two studies in patients with ongoing unstable angina despite medical treatment, who were candidates for coronary angioplasty. In the first study patients were randomized to thrombolytic therapy with alteplase or placebo. In the second study another group of patients with the same syndrome was randomized to CentoRx ${ }^{\mathrm{R}}$ (c7E3) or placebo. Quantitative analysis of coronary angiograms was essential in both studies, both before and after trial drug infusion.

\section{Patients and methods}

\section{Patients selection}

Included in both studies were patients between 21 and 75 years and

- manifesting recurrent episodes of chest pain after hospital admission, occurring at rest and pending medical treatment, with at least one of these episodes with concomitant reversible ST-T segment changes or persistent negative $\mathrm{T}$-waves on the electrocardiogram;

- undergoing a diagnostic coronary arteriogram within 24 hours (alteplase) or 12 hours (c7E3) of the most recent episode of coronary ischemia (chest pain and/or ST-T segment changes);

- exhibiting a 'culprit' coronary lesion in a native vessel suitable for PTCA. A single vessel must be clearly indicated as ischemia related. Total occlusion of this vessel was considered acceptable for angioplasty, if it showed signs of recent occlusion such as the presence of intracoronary thrombi or contrast-staining at the obstruction site;

- ability to perform a second coronary angiogram followed by angioplasty within 24 hours after randomization;

- providing informed consent after completion of the first diagnostic angiogram and prior to the initiation of protocol specific measures.

Excluded for both studies were patients exhibiting features of ongoing ischemia which required immediate intervention, prior PTCA of the same coronary segment within 6 months, recent major trauma including resuscitation, gastro intestinal or urinary tract bleeding within 3 months, persistent hypertension and known bleeding disorders. The c7E3 trial also excluded patients with prior Q-wave myocardial infarction within 7 days, and patients with a platelet count of less than $100,000 / \mathrm{mm}^{3}$.

\section{Medical treatment}

Patients were designated as refractory unstable angina if anginal attacks continued despite bed rest and medical treatment which required minimally i.v. heparin and oral or i.v. nitroglycerin. After randomization all patients were treated with the following combination of medication: 
- heparin 1,000 IU/hour, or a dose sufficient to prolong the activated partial thromboplastin time to twice the control value, after a bolus injection of 5,000 IU of heparin;

- intravenous nitroglycerin ranging in dose from 50 to $300 \mu \mathrm{g} / \mathrm{min}$;

- metoprolol 50-200 $\mathrm{mg}$, in order to reduce heart rate to 60 beats/min;

- nifedipine in a dose of 40-120 mg/day.

After informed consent and randomization by a telephone answering service, study drug infusion was started as soon as possible, but at least within 4 hours after the first angiogram.

For the alteplase trial a bolus injection of $10 \mathrm{mg}$ i.v. was followed by an infusion of $50 \mathrm{mg}$ in the first hour and $20 \mathrm{mg}$ /hour for the subsequent 2 hours. Thus a total amount of $100 \mathrm{mg}$ of alteplase or placebo was administered in 3 hours.

For the c7E3 trial, patients received a bolus dose of $0.25 \mathrm{mg} / \mathrm{kg}$ followed by a $10 \mu \mathrm{g} / \mathrm{min}$ continuous infusion for at least 18 hours. Patients to receive placebo were administered a bolus of human serum albumin, likewise followed by continuous infusion. The infusion continued until one hour following the completion of PTCA.

Alteplase (Actilyse ${ }^{\mathrm{R}}$ ) was supplied by Boehringer Ingelheim International, and c7E3 $\left(\right.$ CentoRx $\left.{ }^{R}\right)$ by Centocor, Malvern PA.

\section{Coronary arteriography and angioplasty}

Coronary arteriography and left ventricular angiography were performed as soon as possible after the qualifying anginal attack using the Judkins technique. Heparin 2,500 to 5,000 IU was administered at the beginning of the procedure. A second angiogram was performed within 24 hours after the start of study medication followed by angioplasty. The coronary artery responsible for the ischemia was identified by means of electrocardiographic location of the reversible ST-T segment changes, and left ventricular wall contraction abnormalities. At least two orthogonal projections were made of the culprit coronary artery, after injection of 1-3 mg of isosorbide dinitrate. During the first and the second angiogram the same projections and X-ray gantry setting were employed to compare lesion severity. Low osmolar contrast medium (iopamidol) was used for all angiograms. All coronary and left ventricular angiograms were scored by at least two observers who were blinded with respect to the treatment assign- ment. Qualitatively the following iterns were scored after the first contrast injection:

- TIMI flow grade [22] of the culprit artery;

- presence of intracoronary thrombus, defined as an intraluminal filling defect, visible during at least one complete cine-run, and surrounded on 3 sides by contrast medium [23]. A total occluded coronary artery could contain a filling defect, but was not automatically scored as containing such a defect;

- stenosis severity as visually assessed in multiple projections.

\section{Quantitative analysis of coronary angiograms}

\section{Quantitative coronary angiography}

All cineangiograms were analyzed with the computerassisted cardiovascular angiography analysis system by the Core laboratory at Cardialysis, Rotterdam, NL. This system has been discussed in detail previously $[24,25]$. The important steps will be briefly described. Any area sized $6.9 \times 6.9 \mathrm{~mm}$ in a selected cineframe (overall dimensions $18 \times 24 \mathrm{~mm}$ ) encompassing the desired arterial segment can be digitized by a highresolution CCD-camera with a resolution of $512 \times$ 512 pixels and 8 bits of gray level. Vessel contours are determined automatically based on the weighted sum of the first and second derivative functions applied to the digitized brightness information along scanlines perpendicular to the local centerline directions of an arterial segment. A computer-derived estimation of the original arterial dimension at the site of the obstruction is used to define the interpolated reference diameter. This technique is based on a computer-derived estimation of the original diameter values over the analyzed region (assuming there was no disease present) according to the diameter function. The absolute diameter of the stenosis as well as the reference diameter are measured by the computer, which used the known guiding catheter diameter as a calibration factor. All contour positions of the catheter and arterial segments are corrected for pincushion distortion.

'Plaque area' is the difference in area in $\mathrm{mm}^{2}$ between the reference and the detected contours over the length of the lesion [26].

The second angiogram to be followed by angioplasty was performed between 12 and 24 hours in the alteplase trial and between 18 and 24 hours in the c7E3 trial after the start of drug administration. Angiograms of the culprit artery were obtained in the same projec- 
Table 1. Baseline clinical, electrocardiographic and angiographic characteristics of patient groups.

\begin{tabular}{|c|c|c|c|c|}
\hline $\begin{array}{l}\text { Group } \\
\mathrm{N}\end{array}$ & $\begin{array}{l}\text { Alteplase } \\
19\end{array}$ & $\begin{array}{l}\text { Placebo } \\
17 \\
\end{array}$ & $\begin{array}{l}\text { c7E3Fab } \\
30\end{array}$ & $\begin{array}{l}\text { Placebo } \\
30\end{array}$ \\
\hline Male/Female & $16 / 3$ & $13 / 4$ & $20 / 10$ & $24 / 6$ \\
\hline Mean age (years) & 59 & 62 & 61 & 60 \\
\hline Previous infarct & 7 & 10 & 9 & 16 \\
\hline Previous $\mathrm{CABG}$ & 0 & 1 & 0 & 2 \\
\hline Previous PTCA & & & 4 & 5 \\
\hline \multicolumn{5}{|c|}{ Medication prior to qualifying ischemic attack } \\
\hline Heparin & 11 & 12 & 26 & 27 \\
\hline Aspirin & 5 & 5 & 21 & 23 \\
\hline \multicolumn{5}{|l|}{ Nitrates } \\
\hline${ }^{*}$ intravenous & 9 & 9 & 24 & 27 \\
\hline * oral & 4 & 5 & 4 & 2 \\
\hline$\beta$-Blocker & 16 & 9 & 22 & 24 \\
\hline Calcium channel blocker & 7 & 11 & 15 & 22 \\
\hline \multicolumn{5}{|l|}{ Ischemia related vessel } \\
\hline Left anterior descending artery & 11 & 6 & 16 & 14 \\
\hline Left circumflex artery & 2 & 4 & 8 & 6 \\
\hline Right coronary artery & 6 & 7 & 6 & 10 \\
\hline Multivessel disease & 5 & 5 & $6^{*}$ & $15^{*}$ \\
\hline \multicolumn{5}{|l|}{ Ejection fraction } \\
\hline$<0.50$ & 3 & 2 & n.a. & n.a. \\
\hline$\geq 0.50$ & 16 & 14 & & \\
\hline Unknown & 0 & 1 & & \\
\hline
\end{tabular}

$\mathrm{CABG}=$ coronary artery bypass grafting; $\mathrm{PTCA}=$ percutaneous transluminal coronary angioplasty; n.a. $=$ not assessed, $* \mathrm{p}=0.03$.

tions as during the first angiogram, after intracoronary injection of isosorbide dinitrate.

\section{Assessments}

The efficacy of treatment was assessed in several ways:

-Frequency of recurrent ischemic events between the first and the second angiogram (maximal 24 hours).

-Incidence of major events, defined as death, myocardial infarction or urgent intervention during this observation period and during and after angioplasty.

- Quantitative and qualitative analysis of all angiograms, before and after study drug infusion.

\section{Statistical analysis}

Differences between groups were analyzed with a twotailed Student $t$ test. Changes in quantitatively mea- sured coronary artery severity stenosis in each group were compared with a two-tailed paired $t$ test. Differences in incidence of recurrent ischemic attacks, myocardial infarction and presence of intracoronary clots were determined between treatment and respective placebo groups with Fisher's exact test.

\section{Results}

\section{Baseline characteristics}

The alteplase/placebo study was conducted between November 1987 and April 1989 in one hospital. The c7E3 Fab/placebo trial enrolled patients between September 1991 and July 1992 in five different hospitals. Baseline characteristics of the patients enrolled in both studies are summarized in Table 1. More patients in both placebo groups had sustained a previous infarct compared with the treatment groups, but 
left ventricular ejection fraction was similar in the alteplase/placebo groups, while this parameter was not assessed in the c7E3 Fab/placebo study. Also significantly more patients in the placebo group from the last trial demonstrated multivessel disease, defined as a more than $50 \%$ diameter stenosis in one of the three main epicardial vessels. All other baseline parameters were similar between each treatment and respective placebo group.

\section{Recurrent ischemia}

Between the start of drug infusion and the second angiogram 5, 6, 9 and 16 patients from the alteplase, placebo, c7E3 Fab and placebo group respectively, had one or more episodes of recurrent ischemia defined as chest pain, with or without ECG changes. Severe recurrent ischemia, not subsiding with medical measures, necessitated urgent coronary angioplasty in 4,1 , 0 and 3 patients from the alteplase, placebo, c7E3 Fab and placebo groups respectively.

\section{Major events}

In the two studies a major event defined as death, myocardial infarction or urgent intervention occurred in $7,3,1$ and 7 patients from the alteplase, placebo, c7E3 Fab and placebo group respectively. The nature of these major events in all four groups is summarized in Table 2.

Death in the alteplase patient occurred 48 hours after angioplasty, complicated by dissection of the right common iliac artery and retroperitoneal hemorrhage.

One other patient from the placebo group in the c7E3 Fab study died, 26 days after allocation after a complicated clinical course, including two urgent PTCA procedures and myocardial infarction.

\section{Qualitative evaluation of coronary angiograms}

TIMI flow grade 3 in culprit arteries, assessed centrally by the Core Laboratory, was present in 57 to $76 \%$ of all patients at the first angiogram. Of all 4 groups studied, a substantial improvement in coronary blood flow occurred after treatment in the c7E3 Fab patient group only, while all three other groups showed both improvement and deterioration in TIMI flow score (Table 3).

Extensive filling defects in the coronary arteries were seldom encountered. Most filling defects were single, visible in more than one direction and located

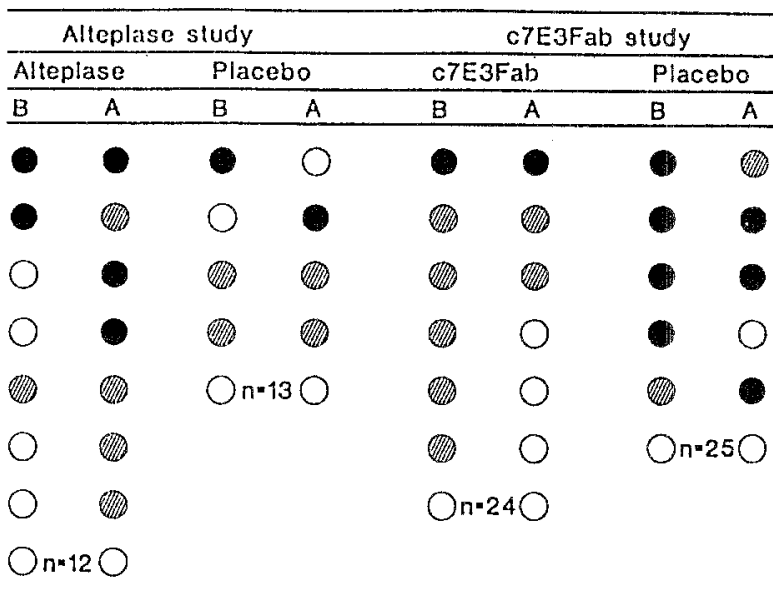

Fig. 1. Qualitative coronary angiographic data of the ischemia related coronary artery before (B) and after (A) study drug infusion.

- Totally occluded coronary artery Intracoronary filling defect $\bigcirc$ Patent coronary artery, without filling detect Note: The number of non totally occluded vessels, without filling defects in both angiograms, is depicted in the bottom line.

Table 2. Major events in all 4 study groups.

\begin{tabular}{|c|c|c|c|c|}
\hline $\mathrm{N}$ & $\begin{array}{l}\text { Alteplase } \\
19\end{array}$ & $\begin{array}{l}\text { Placebo } \\
17\end{array}$ & $\begin{array}{l}\text { c7E3Fab } \\
30\end{array}$ & $\begin{array}{l}\text { Placebo } \\
30\end{array}$ \\
\hline Death & 1 & 0 & 0 & 1 \\
\hline Myocardial infarction & 7 & 3 & 1 & 4 \\
\hline Before PTCA & 4 & 1 & 0 & 1 \\
\hline After PTCA & 3 & 2 & 1 & 3 \\
\hline Urgent procedure & 5 & 1 & - & 7 \\
\hline PTCA & 4 & 1 & - & 3 \\
\hline $\mathrm{CABG}$ & 1 & - & - & 3 \\
\hline Stent & - & - & - & 1 \\
\hline $\begin{array}{l}\text { Total nr of patients } \\
\text { with one or more } \\
\text { major events }\end{array}$ & 7 & 3 & 1 & 7 \\
\hline
\end{tabular}

$\mathrm{CABG}=$ coronary artery bypass grafting;

PTCA = percutaneous transluminal coronary angioplasty.

distally from the culprit lesion. The number of intracoronary clots, and total occlusions from both studies, in the pre and post treatment angiogram are shown in Fig. 1. In the alteplase study new occlusions of culprit arteries occurred in both groups, while other occluded coronary arteries became patent after study drug infusion. In the c7E3 Fab study a new occlusion was observed in the placebo group only, but also restored patency of a total occluded vessel in two cases with thrombotic remnants in one case. Three out of five 
Table 3. Qualitative angiographic data.

\begin{tabular}{|c|c|c|c|c|c|c|c|c|}
\hline Group & \multicolumn{2}{|c|}{ Alteplase } & \multicolumn{2}{|c|}{ Placebo } & \multicolumn{2}{|c|}{$\mathrm{c} 7 \mathrm{E} 3 \mathrm{Fa}$} & \multicolumn{2}{|c|}{ Placebo } \\
\hline $\mathbf{N}$ & & 19 & & 17 & & 30 & & 30 \\
\hline TIMI flow & B & $\mathrm{A}$ & $\mathrm{B}$ & $\mathrm{A}$ & $\mathrm{B}$ & $\bar{A}$ & B & $\mathrm{A}$ \\
\hline 0 & 2 & 3 & 1 & 1 & 1 & 1 & 4 & 3 \\
\hline 1 & 0 & 0 & 0 & 0 & 2 & 1 & 0 & 1 \\
\hline 2 & 3 & 3 & 3 & 2 & 10 & 5 & 7 & 6 \\
\hline 3 & 14 & 13 & 13 & 14 & 17 & 23 & 19 & 20 \\
\hline Improved & & 3 & & 2 & & 6 & & 4 \\
\hline Worsened & & 4 & & 2 & & 0 & & 3 \\
\hline Intracoronary filling defect & 1 & 4 & 2 & 2 & 5 & 2 & 1 & 1 \\
\hline
\end{tabular}

Table 4. Quantitative angiographic data from the first angiogram (I) and after study drug infusion (II) and the difference between both measurements (II-I).

\begin{tabular}{|c|c|c|c|c|c|c|c|c|}
\hline \multirow{2}{*}{$\begin{array}{l}\text { Treatment } \\
\text { Variable }\end{array}$} & \multicolumn{2}{|c|}{ Alteplase $(n=19)$} & \multicolumn{2}{|c|}{ Placebo $(n=17)$} & \multicolumn{2}{|c|}{ c7E3Fab $(n=30)$} & \multicolumn{2}{|c|}{ Placebo $(n=30)$} \\
\hline & $\mathrm{n}$ & & $\mathrm{n}$ & & n & & $\mathrm{n}$ & \\
\hline \multicolumn{9}{|l|}{$\operatorname{DS}(\%)$} \\
\hline I & 19 & $66.7(16.1)$ & 17 & $63.1(13.1)$ & 30 & $65.7(8.6)$ & 29 & $67.7(16.1)$ \\
\hline II & 19 & $67.0(14.8)$ & 17 & $61.6(13.5)$ & 30 & $62.3(10.5)$ & 29 & $65.6(15.8)$ \\
\hline II-I & 19 & $0.3(20.2)$ & 17 & $-1.6(16.2)$ & 30 & $-3.4(6.7)^{*}$ & $29^{\circ}$ & $-2.1(12.4)$ \\
\hline \multicolumn{9}{|c|}{$\operatorname{MLD}(\mathrm{mm})$} \\
\hline I & 19 & $1.0(0.4)$ & 17 & $1.1(0.5)$ & 30 & $0.9 \quad(0.3)$ & 30 & $0.9 \quad(0.4)$ \\
\hline II & 19 & $0.9(0.4)$ & 17 & $1.1(0.5)$ & 30 & $1.0(0.3)$ & 30 & $0.9 \quad(0.4)$ \\
\hline II-I & 19 & $-0.1(0.6)$ & 17 & $0.0 \quad(0.4)$ & 30 & $0.1 \quad(0.2)$ & 30 & $0.0 \quad(0.3)$ \\
\hline \multicolumn{9}{|c|}{ Ext $\mathrm{Ob}(\mathrm{mm})$} \\
\hline I & 17 & $7.1 \quad(2.2)$ & 16 & $9.2(4.0)$ & 29 & $7.3(2.2)$ & 26 & $7.2 \quad(3.4)$ \\
\hline II & 17 & $7.0 \quad(2.6)$ & 16 & $7.8 \quad(3.3)$ & 29 & $6.9(2.1)$ & 26 & $7.3 \quad(2.9)$ \\
\hline II-I & 16 & $-0.1(1.4)$ & 15 & $-0.9(2.0)$ & 29 & $-0.5(1.2)^{*}$ & 26 & $0.3 \quad(1.8)$ \\
\hline \multicolumn{9}{|c|}{ Plq Area $\left(\mathrm{mm}^{2}\right)$} \\
\hline I & 17 & $10.0(5.3)$ & 16 & $12.0(7.6)$ & 29 & $8.2(3.4)$ & 29 & $9.1 \quad(6.8)$ \\
\hline II & 17 & $9.5 \quad(6.8)$ & 16 & $8.9 \quad(5.3)$ & 29 & $7.1 \quad(2.5)$ & 27 & $8.6(4.8)$ \\
\hline II-I & 15 & $-0.2(3.0)$ & 15 & $-2.1(3.6)^{*}$ & 29 & $-1.1(1.9)^{*}$ & 25 & $-0.5 \quad(3.3)$ \\
\hline \multicolumn{9}{|l|}{ AS (\%) } \\
\hline 1 & 14 & $87.7 \quad(9.6)$ & 15 & $84.6(15.7)$ & 20 & $89.2 \quad(6.7)$ & 21 & $90.7 \quad(7.9)$ \\
\hline II & 16 & $88.2(8.4)$ & 14 & $85.5(17.4)$ & 23 & $88.3 \quad(8.4)$ & 22 & $89.6(10.2)$ \\
\hline II-I & 12 & $-1.1(10.4)$ & 14 & $1.1 \quad(9.6)$ & 19 & $1.8 \quad(8.1)$ & 19 & $-1.3(6.4)$ \\
\hline
\end{tabular}

DS = diameter stenosis; $\mathrm{MLD}=$ miminal lumen diameter; $\mathrm{AS}=$ area stenosis; Ext $\mathrm{Ob}=$ extent of the obstruction;

Plq area $=$ plaque area; $*$ p [PI]DW 0.05. Data are given as mean values (standard deviation).

coronary clots resolved in the treatment group of the c7E3 study.

\section{Quantitative coronary angiographic analysis}

Quantitative coronary angiographic data are summarized in Table 4. One patient from the c7E3 Fab study 
with a very proximal LAD lesion is missing in the calculated percentage diameter stenosis, because the reference diameter could not be ascertained. All videodensitometric area calculations of more than $100 \%$ obstruction were left out, while plaque area and extent of obstruction could naturally only be calculated in patent coronary arteries.

In the alteplase study, no significant changes were observed in the quantitative parameters nor within nor between groups.

In the c7E3 Fab study significant decreases in percentage diameter stenosis, extent of obstruction and plaque area were observed in the c7E3 Fab patients.

In the placebo group the same changes were observed to a lesser extent, except for the extent of obstruction, which decreased in the c7E3 Fab patients, but increased in the placebo group patients. Differences between groups were not significant.

\section{Discussion}

When thrombolytic therapy revived for the treatment of acute myocardial infarction and showed beneficial effects, a logic next step was to add thrombolytics to the drug regimen of patients with ongoing unstable angina refractory to that regimen. Several studies have been conducted since using different thrombolytic agents in different classes of unstable angina [1120, 27-31]. Only the study of Gold, including only 23 patients, showed a beneficial reduction in cardiac events from $55 \%$ to $9 \%$. And although inclusion criteria varied in the interval between the last anginal attack and study drug infusion, in the classification according to Braunwald, and the presence of angiographically demonstrated significant coronary artery disease, all shared a common outcome of no clinical benefit. Only the study of Ardessino [28] showed a lower mortality in the group treated with alteplase, all other studies manifesting an equal [19] or higher mortality in the group treated with a thrombolytic agent $[13,18-20,30,31]$. Also the incidence of myocardial infarction during and after treatment with thrombolytic agents was higher in the treated patients than in those receiving placebo (29 of 270 and 15 of 289 patients respectively), while both groups were on intravenous heparin as background therapy $[12,13,17-20,29,31$, 32].

Some studies included quantitative analysis of coronary angiograms before and after study drug infusion, the angiography result being part of the inclu- sion process $[12,13,17,19,20,28,31]$. These studies all showed a minimal reduction in percentage diameter stenosis, both in the treatment and placebo groups, reaching only statistical significance in the treated group in two studies [17, 20]. Part of the problem of most studies was the small number of patients included, varying from 24 to 159 patients. The two studies with a significant reduction in diameter stenosis in the treated groups included a relatively large number of patients of 70 and 159 respectively.

The thrombolytic study reported here treating patients with refractory unstable angina showed a high incidence of cardiac events in both groups, possibly reflecting the severe nature of the syndrome in these patients, already treated with routine medication, including heparin and aspirin.

Two recent editorials addressed the relative inefficacy of thrombolytic agents in patients with unstable angina [9, 33]. They both explain the apparent discrepancy between the effects of thrombolytic agents in myocardial infarction and unstable angina pectoris by the difference in underlying disease and enhanced thrombosis formation. Opening of an occluded artery as in myocardial infarction, and keeping an artery open as in unstable angina require different approaches. In the Unasem study e.g. a significant reduction in diameter stenosis was only achieved by opening occluded arteries with anisoylated plasminogen streptokinase activator complex [20]. Several studies suggest that thrombolytic therapy might enhance thrombin formation and activate platelets to further coronary thrombosis [34-40]. These effects of tissue plasminogen activator can be countered by the monoclonal antiplatelet GPIIb/IIIa receptor antibody as has been demonstrated in a canine model [41].

It is conceivable that this antibody alone prevents occlusion of coronary arteries in unstable angina and prevents platelet aggregation. In fact we demonstrated that c7E3 Fab ameliorated the clinical course of patients with refractory unstable angina. Also the modest but significant reduction in diameter stenosis of the culprit lesion corroborates these optimistic expectations.

These results look quite promising and might be confirmed in a larger trial which is now underway. Quantitative assessment of coronary arteriograms could make the clinical results more understandable, all the more because the absence of clinical benefit in patients with unstable angina pectoris treated with thrombolytic agents has not been attended by quantitative improvement of coronary artery lesions. 


\section{Acknowledgement}

We gratefully acknowledge the technical assistance of Karin Nijssen and Dini Amo in analyzing the data and the angiograms. The secretarial assistance of Marja Lems is also gratefully acknowledged.

\section{References}

1. Braunwald A. Unstable angina. A classification. Circulation 1989; 80: 410-4.

2. Fuster V, Badimon L, Cohen M, Ambrose JA, Badimon JJ, Chesebro J. Insights into the pathogenesis of acute ischemic syndromes. Circulation 1988; 77: 1213-20.

3. Falk E. Morphologic features of unstable atherothrombotic plaques underlying acute coronary syndromes. Am J Cardiol 1989; 63: 114E-20E.

4. Theroux P, Quimet H, McCans J, Latour JG, Joly P, Levy G et al. Aspirin, heparin, or both to treat acute unstable angina. $N$ Engl J Med 1988; 319: 1105-11.

5. Goldman BS, Katz A, Christakis G, Weisel R. Determinants of risk for coronary artery bypass grafting in stable and unstable angina pectoris. Can J Surg 1985; 28: 505-8.

6. de Feyter PJ, Suryapranata H, Serruys PW, Beatt K, van Domburg $R$, van den Brand $M$ et al. Coronary angioplasty for unstable angina: Immediate and late results in 200 consecutive patients with identification of risk factors for unfavorable early and late outcome. J Am Coll Cardiol 1988; 12: 324-33.

7. Verstraete M, Brower RW, Collen D, Dunning AJ, Lubsen $\mathrm{J}$, Michel PL et al. Double-blind randomised trial of intravenous tissue-type plasminogen activator versus placebo in acute myocardial infarction. The Lancet $1985 ; 2$ : 965-9.

8. Van de Werf F, Arnold AER. Intravenous tissue plasminogen activator and size of infarct, left ventricular function, and survival in acute myocardial infarction. Br Heart $\mathbf{J} 1988 ; 297$ : 1374-9.

9. Leinbach RC. Thrombolysis in unstable angina. Circulation 1992; 85: 376-7.

10. Shapiro EP, Brinker JA, Gottlieb SO, Guzman PA, Bulkley BH. Intracoronary thrombolysis 3 to 13 days after acute myocardial infarction for postinfarction angina pectoris. Am J Cardiol 1985; 55: 1453-8.

11. Lawrence JR, Shepherd JT, Bone I, Rogen AS, Fulton WFM. Fibrinolytic therapy in unstable angina pectoris, a controlled clinical trial. Thromb Res $1980 ; 17: 767-77$.

12. Gold HK, Johns JA, Leinbach RC, Yasuda T, Grossbard E, Zusman $\mathrm{R}$ et al. A randomized, blinded, placebo-controlled trial of recombinant human tissue-type plasminogen activator in patients with unstable angina pectoris. Citculation 1987;75: 1192-9.

13. Topol EJ, Nicklas JM, Kander NH, Walton JA, Ellis SG, Gorman $L$ et al. Coronary revascularization after intravenous tissue plasminogen activator for unstable angina pectoris: Results of a randomized, double-blind placebo controlled trial. Am J Cardi ol $1988 ; 62: 368-71$.

14. Ambrose JA, Hjemdahl-Monsen C, Borrico S, Sherman W, Cohen M, Gorlin R et al. Quantitative and qualitative effects of intracoronary streptokinase in unstable angina and non $Q$ wave infarction. J Am Coll Cardiol 1987; 9: 1156-65.
15. de Zwaan C, Bär F, Janssen JHA, de Swart HB, Vermeer F, Wellens HJJ. Effects of thrombolytic therapy in unstable angina: Clinical and angiographic results. J Am Coll Cardiol 1988; 12: 301-9.

16. Gotoh K, Minamino T, Katoh O, Hamano Y, Fukui S, Hori $\mathrm{M}$ et al. The role of intracoronary thrombus in unstable angina: Angiographic assessment and thrombolytic therapy during ongoing anginal attacks. Circulation 1988; 77: 526-34.

17. Williams DO, Topol EJ, Califf RM, Roberts R, Mancini GBJ, Joelson JM et al. Intravenous recombinant tissue-type plasminogen activator in patients with unstable angina pectoris. Results of a placebo-controlled, randomized trial. Circulation $1990 ; 82: 376-83$.

18. Neri Serneri GG, Gensini GF, Poggesi L, Trotta F, Modesti PA, Boddi $\mathrm{M}$ et al. Effect of heparin aspirin, or alteplase in reduction of myocardial ischaemia in refractory unstable angina. Lancet 1990; 335: 615-8.

19. Freeman MR, Langer A, Wilson RF, Morgan CD, Armstrong PW. Thrombolysis in unstable angina. Randomized doubleblind trial of t-PA and placebo. Circulation 1992; 85: 150-7.

20. Bär FW, Verheugt FW, Col J, Materne P, Monassier JP, Geslin PG et al. Thrombolysis in patients with unstable angina improves the angiographic but not the clinical outcome. Results of UNASEM, a multicenter, randomized placebo-controlled, clinical trial with anistreplase. Circulation 1992; 86: 131-7.

21. Gold HK, Gimple LW, Yasuda T, Leinbach RC, Werner W, Holt $R$ et al. Pharmacodynamic study of $F\left(a b^{\prime}\right)_{2}$ fragments of murine monoclonal antibody $7 \mathrm{E} 3$ directed against human platelet glycoprotein IIb/IIIa in patients with unstable angina pectoris. J Clin Invest 1990; 86: 651-9.

22. Chesebro JH, Knatterud G, Roberts R, Borer J, Cohen LS, Dalen J et al. Thrombolysis in myocardial infarction (TIMI) trial, Phase 1: a comparison between intravenous tissue plasminogen activator and intravenous streptokinase*. Clinical findings through hospital discharge. Circulation 1987; 76: 142-54.

23. Capone G, Wolf NM, Meyer B, Meister SG. Frequency of intracoronary filling defects by angiography in angina pectoris at rest. Am J Cardiol 1985; 56: 403-6

24. Reiber JHC, Serruys PW, Kooijman CJ, Wijns W, Slager CJ, Gerbrands JJ et al. Assessment of short-, medium-, and longterm variations in arterial dimensions from computer assisted quantification of coronary cineangiograms. Circulation 1985; 71:280-8.

25. Strauss BH, Juilliere Y, Rensing BJ, Reiber JHC, Serruys PW. Edge detection versus densitometry for assessing coronary stenting quantitatively. Am J Cardiol 1991; 67: 484-90.

26. Crawford DW, Brooks SH, Selzer RH, Brandt R, Beckenbach ES, Blankenhorn DH. Computer densitometry for angiographic assessment of arterial cholesterol contents and gross pathology in human atherosclerosis.J Lab Clin Med 1977; 89:378-92.

27. Schreiber TL, Macina G, McNulty A, Bunnell P, Kikel M, Miller DH et al. Urokinase plus heparin versus aspirin in unstable angina and non-q-wave myocardial infarction. Am J Cardiol 1989; 64: 840-4.

28. Ardissino D, Barberis P, De Servi S, Mussini A, Rolla A, Visani $L$ et al. Recombinant tissue-type plasminogen activator followed by heparin compared with heparin alone for refractory unstable angina pectoris. Am J Cardiol 1990; 66: 910-4.

29. Schreiber TL, Rizik D, White C, Sharma GVRK, Cowley M, Macina $G$ et al. Randomized trial of thrombolysis versus heparin in unstable angina. Circulation 1992; 86: 1407-14.

30. TIMI-IIIB TRIAL.

31. van den Brand M, van Zijl A, Geuskens R, de Feyter PJ, Serruys $P W$, Simoons $M$. Tissue plasminogen activator in refrac- 
tory unstable angina. A randomized double-blind placebocontrolled trial in patients with refractory unstable angina and subsequent angioplasty. Eur Heart J 1991; 12: 1208-14.

32. Sansa M, Cernigliaro C, Campri A, Simonetti I. Effects of urokinase and heparin on minimal cross-sectional area of the culprit narrowing in unstable angina pectoris. Am J Cardiol 1990; 66: 910-4.

33. Waters D, Lam JYT. Is thrombolytic therapy striking out in unstable angina? Circulation 1992; 86: 1642-4.

34. Rapold HJ. Promotion of thrombin activity by thrombolytic therapy without simultaneous anticoagulation. Lancet 1990; 1: 481-2.

35. Eisenberg PR, Miletich JP. Induction of marked thrombin activity by pharmacologic concentrations of plasminogen activators in nonanticoagulated whole blood. Thromb Res 1990; 55: 63543.

36. Aronson DL, Chang P, Kessler CM. Platelet-dependent thrombin generation after in vitro fibrinolytic treatment. Circulation 1992; 85: 1706-12.

37. Eisenberg PR, Sherman LA, Jaffe AS. Paradoxic elevation of fibrinopeptide A after streptokinase: Evidence for continued thrombosis despite intense fibrinolysis. J Am Coll Cardiol 1987; 10: 527-9.
38. Fitzgerald DJ, Weight F, Fitzgerald GA. Increased thromboxane biosynthesis during coronary thrombolysis: Evidence that platelet activation and thromboxane A2 modulate the response to tissue-type plasminogen activator in vivo. Circ Res 1989; 65: 83-94.

39. Golino P, Ashton JH, Glas-Greenwalt P, McNatt J, Buja LM, Willerson JT. Mediation of reocclusion by thromboxane A2 and serotonin after thrombolysis with tissue-type plasminogen activator in a canine preparation of coronary thrombosis. Circulation 1 988; 77: 678-84.

40. Fitzgerald DJ, Catella F, Roy L, Fitzgerald GA. Marked platelet activation in vivo after intravenous streptokinase in patients with acute myocardial infarction. Circulation 1988 ; 77 : 14250.

41. Gold HK, Coller BS, Yasuda T, Saito T, Fallon JT, Guerrero L et al. Rapid and sustained coronary artery recanalization with combined bolus injection of recombinant tissue-type plasminogen activator and monoclonal antiplatelet GPIIb/IIIa antibody in a canine preparation. Circulation 1988; 77:670-7. 